\title{
EFFECT OF USE OF RECYCLED MATERIALS ON INDIRECT TENSILE STRENGTH OF ASPHALT CONCRETE MIXES
}

\author{
Shunyashree $^{1}$, Tejas Bhavimane ${ }^{2}$, M.R.Archana ${ }^{3}$, M S Amarnath \\ ${ }^{1,2} I V^{1}$ semester, M.Tech, ${ }^{3}$ Assistant Professor, ${ }^{4}$ Professor-Civil Engineering, R.V College of Engineering, Bangalore, \\ India
}

shunyashree@gmail.com,tejasbavimane@ymail.com,archana.mosale@gmail.com,amarnath_ms@rediffmail.com

\begin{abstract}
Depletion of natural resources and aggregate quarries for the road construction is a serious problem to procure materials. Hence recycling or reuse of material is beneficial. On emphasizing development in sustainable construction in the present era, recycling of asphalt pavements is one of the effective and proven rehabilitation processes. For the laboratory investigations reclaimed asphalt pavement (RAP) from NH-4 and crumb rubber modified binder (CRMB-55) was used. Foundry waste was used as a replacement to conventional filler. Laboratory tests were conducted on asphalt concrete mixes with 30, 40, 50, and 60 percent replacement with RAP. These test results were compared with conventional mixes and asphalt concrete mixes with complete binder extracted RAP aggregates. Mix design was carried out by Marshall Method. The Marshall Tests indicated highest stability values for asphalt concrete (AC) mixes with $60 \%$ RAP. The optimum binder content $(O B C)$ decreased with increased in RAP in AC mixes. The Indirect Tensile Strength (ITS) for AC mixes with RAP also was found to be higher when compared to conventional AC mixes at $30^{\circ} \mathrm{C}$.
\end{abstract}

Keywords: Reclaimed asphalt pavement, Foundry waste, Recycling, Marshall Stability, Indirect tensile strength.

\section{INTRODUCTION}

Recycling has been successfully used at many places world over and has shown good performances. Asphalt pavement recycling technology is not so popular in India, but gaining its popularity because of its valuable approach for technical, environmental and economical reasons. By volume, aggregate generally accounts for 92 to 96 percent of $\mathrm{AC}$ and about 70 to 80 percent of Portland cement concrete. Aggregate is also used for base and sub-base courses for both flexible and rigid pavements. Aggregates can either be natural or manufactured. Natural aggregates are generally extracted from larger rock formations through an open excavation. While several factors influence the use of RAP in asphalt pavement, the two primary factors are economic savings and environmental benefits. RAP is a useful alternative to virgin materials because it reduces the use of virgin aggregate and the amount of virgin asphalt binder required in the production of hot mix asphalt. The use of RAP also conserves energy, lowers transportation costs required to obtain quality virgin aggregate, and preserves resources. Additionally, using RAP decreases the amount of construction debris placed into landfills and does not deplete non renewable natural resources such as virgin aggregate and asphalt binder.

\section{LITERATURE REVIEW}

Recycling asphalt creates a cycle that optimizes the use of natural resources and sustains the asphalt pavement industry. Based on the recent studies, in USA, 33 million tons of RAP is used per year for recycling purpose which is around $80 \%$ of the total amount of RAP collected from old bituminous pavements. The amount of RAP used for recycling per year is about 0.84 million tons in Sweden, 7.3 million tons in Germany, 0.53 million tons in Denmark and around 0.12 million tons in Netherlands. Pavement recycling-an overview: This discusses about the various recycling materials and they also study the advantages of RAP over other recycling material. Which includes, According to a report published by the Federal Highway Administration (1997), in the United States of America, asphalt pavement is the most recycled product (in terms of tonnage) compared to others such as newsprint, glass bottles, aluminum cans and plastic containers. The conclusion is as follows, as resources become scarcer and environmental concern becomes more widespread, it is anticipated that pavement recycling will become more important in the coming years. Use and Reuse of materials have gained high importance in recent years. Depleting natural resources, reuse of available resources can effectively cut down cost and save environment. The literature review indicates that not many studies are on use of reclaimed asphalt pavement in bituminous mixes have been tried hence necessitating the study.

\subsection{Need for Study}

The main emphasis of this study was to reuse the high invested pavement material for its best instead of burying it in underneath layers over the new pavement. Depleting natural resources and increase in cost gives way to use of RAP for the 
pavement. Reuse of available resources can effectively cut down cost and save environment. Though use of RAP in base and sub base courses have been explode, full fledged use is yet to be undertaken under field conditions. Also, use of RAP in binder courses is less explored. In this work an effort has been taken up to throw light on use of RAP in bituminous concrete grade I mixes with laboratory investigations.

\subsection{Objectives of Present Paper}

1. To evaluate the improvement or changes in Marshall properties namely stability, flow, bulk density, voids in mineral aggregates (VMA), voids filled with bitumen (VFB), optimum binder content for AC mixes with varying percentage of RAP.

2. To compare the Marshall properties of AC mixes with RAP and AC mixes with conventional aggregates and bitumen or binder extracted aggregates.

3. To study the indirect tensile strength behaviour of asphalt concrete mixes with conventional aggregate, binder extracted aggregates and varying percentages of Rap at $30^{\circ} \mathrm{C}$.

\section{METHODOLOGY}

For the present study RAP has been procured from the surface course BC grade I of NH-4 from Sira near Tumkur. Black sand a by-product from the foundry industry has been used as filler in AC mix. Crumb rubber modified bitumen (CRMB-55) has been used as the binder material since the procured RAP contained the CRMB-55 binder. For the present study, an attempt has been made to investigate the effect of RAP in asphalt concrete.RAP without binder extraction has been tried at trial percentages of $30,40,50$, and 60 . For comparison, laboratory properties of AC mixes with conventional aggregate was tried. Also an attempt has been made to use binder extracted RAP aggregate in AC mixes. In all the cases, foundry waste has been used as replacement to conventional fine aggregates and filler.

Coarse aggregates: Conventional aggregate were collected from local quarry. These were replaced with 30, 40, 50 and 60 percentage of RAP. Hence basic properties of both conventional and RAP were conducted and are as presented in Table1.

Fine aggregates: Foundry waste has been used as fine aggregate in extracted RAP AC mixes for the size 300 and 150 microns, For 30, 40, 50, 60, percentages of RAP AC mixes $2.36 \mathrm{~mm}$ and $1.18 \mathrm{~mm}$ RAP fines are used. Conventional aggregates are used for missing blending proportions of RAP. For binder extracted RAP aggregates foundry waste are used as substitute for fine aggregate.

Table 1 Basic properties of conventional and RAP aggregates

\begin{tabular}{|c|c|c|c|c|}
\hline SI no & Aggregate tests & $\begin{array}{c}\text { Conventional } \\
\text { aggregates }\end{array}$ & $\begin{array}{c}\text { RAP } \\
\text { aggregates }\end{array}$ & $\begin{array}{c}\text { Requirements as per Table 500-14 of } \\
\text { MoRT\&H } \\
\text { (IV revision) } \\
\text { Specifications }\end{array}$ \\
\hline 1 & Crushing value (\%) & 22.7 & 21.1 & Max 30\% \\
\hline 2 & Impact value (\%) & 19 & 16.08 & Max 27\% \\
\hline 3 & Los Angeles abrasion value (\%) & 21.50 & 20 & Max 35\% \\
\hline 4 & $\begin{array}{c}\text { Flakiness and Elongation Index } \\
\text { (Combined) (\%) }\end{array}$ & 29.52 & 26 & Max 2\% \\
\hline 5 & $\begin{array}{c}\text { Water absorption (\%) } \\
6\end{array}$ & $\begin{array}{c}\text { Aggregate specific gravity } \\
\text { 1.Coarse aggregate } \\
\text { 2.Fine aggregate }\end{array}$ & $\begin{array}{c}2.65 \\
2.7\end{array}$ & $\begin{array}{c}2.69 \\
2.31\end{array}$ \\
\hline
\end{tabular}

Filler: The foundry collected is a byproduct which is used as a raw material for cement industry. Fills the voids between the fine aggregates, stiffens the binder and offers permeability. Black sand byproduct of foundry industry was used as filler in asphalt mix. The foundry waste was collected from Dakshin industry near Hoskote, Bangalore. The chemical composition of foundry waste is as shown in table 2. The percentage of silica being $89.49 \%$ encouraged the use of foundry waste as fine aggregates and filler as a replacement to conventional aggregate and cement respectively. Specific gravity of foundry waste was found to be 2.56 . 
Table 2 Chemical composition of Foundry waste

\begin{tabular}{|c|c|c|}
\hline Sl.No & Parameter & Value (\%) \\
\hline 1 & Calcium Carbonate & 0.60 \\
\hline 2 & Magnesium Carbonate & 0.10 \\
\hline 3 & Silica & 89.49 \\
\hline 4 & Titanium di Oxide & 0.68 \\
\hline 5 & Alumina & 2.40 \\
\hline 6 & Manganese Oxide & 0.03 \\
\hline 7 & Magnesium Oxide & 0.03 \\
\hline 8 & Calcium Oxide & 0.34 \\
\hline 9 & Potassium Oxide & 2.60 \\
\hline 10 & Phosphorus Pentoxide & 0.01 \\
\hline 11 & Barium Oxide & 0.03 \\
\hline 12 & Loss of Ignition & 3.68 \\
\hline
\end{tabular}

Source: Raghavendra Spectro Metallurgical Laboratory, Bangalore.

Binder: Fills the voids and also cause particle adhesion. Crumb rubber modified bitumen (CRMB-55) is used in the mix as the procured RAP contained the same binder in the aggregates which was used without extraction.

Table 3 Basic properties of Crumb rubber modified bitumen (CRMB-55)

\begin{tabular}{|c|c|c|c|}
\hline $\begin{array}{l}\text { SL } \\
\text { No. }\end{array}$ & Test Conducted & Test results & $\begin{array}{l}\text { Requirements as per } \\
\text { IRC SP:53-2002 }\end{array}$ \\
\hline 1 & Penetration at $25^{\circ} \mathrm{C}, 0.1 \mathrm{~mm}, 100 \mathrm{gm}, 5 \mathrm{sec}$ & 56 & $<60$ \\
\hline 2 & Softening point $(\mathrm{R} \& \mathrm{~B}),\left({ }^{0} \mathrm{C}\right)$ & 56 & $55($ minimum $)$ \\
\hline 3 & Flash point, ${ }^{0} \mathrm{C}$ & 310 & 220 (minimum) \\
\hline 4 & $\begin{array}{l}\text { Elastic Recovery of half thread in ductilometer at } \\
\qquad 15^{\circ} \mathrm{C}, \%\end{array}$ & 60 & 50 (minimum) \\
\hline \multicolumn{4}{|c|}{ Thin film oven test (TFTO) on residue } \\
\hline 5 & Penetration at $25^{\circ} \mathrm{C}, 0.1 \mathrm{~mm}, 100 \mathrm{gm}, 5 \mathrm{sec}$ & 64 & $60($ minimum $)$ \\
\hline 6 & Increase in softening point $(\mathrm{R} \& \mathrm{~B}),\left({ }^{0} \mathrm{C}\right)$, & 5 & 6(maximum) \\
\hline 7 & $\begin{array}{l}\text { Elastic Recovery of half thread in ductilometer at } \\
\qquad 25^{\circ} \mathrm{C}, \%\end{array}$ & 45 & 35(minimum) \\
\hline
\end{tabular}


Aggregate gradation: Bituminous concrete mix of grading-I, was chosen as per clause 500-18, of MoRT\&H (IV revision) specifications. Table 4 shows the gradation adopted for the mix.

Table 4 Aggregate gradation as per MoRT\&H (IV revision) for Asphalt concrete grade-I mix

\begin{tabular}{|c|c|c|c|}
\hline Sieve size in, mm & Adopted mid gradation & $\begin{array}{c}\text { \% Weight } \\
\text { Retained }\end{array}$ & $\begin{array}{c}\text { Weight retained, } \\
\text { grams }\end{array}$ \\
\hline $26.5-19$ & 89.5 & 10.5 & 129 \\
\hline $19-13.2$ & 69 & 20.5 & 247 \\
\hline $13.2-9.5$ & 62 & 7 & 88 \\
\hline $9.5-4.75$ & 45 & 17 & 111 \\
\hline $4.75-2.36$ & 36 & 9 & 111 \\
\hline $2.36-1.18$ & 27 & 9 & 76 \\
\hline $1.18-0.6$ & 21 & 6 & 80 \\
\hline $0.6-0.3$ & 15 & 6 & 76 \\
\hline $0.3-0.15$ & 9 & 6 & 53 \\
\hline $0.15-0.75$ & 5 & 4 & \\
\hline
\end{tabular}

\section{MARSHALL METHOD OF MIX DESIGN}

Marshall Tests were conducted for asphalt concrete mixes prepared with replacement of conventional coarse and fine aggregate with RAP and filler with foundry waste with trial percentages of 30, 40, 50, and 60. For comparison Marshall tests were conducted on asphalt concrete mixes with binder extracted RAP aggregate and conventional aggregates. CRMB-55 was used as binder since the source of RAP contained the same binder. Foundry waste was used to replace the conventional fine aggregate and filler. The Marshall test results for AC mixes with conventional and bitumen extracted RAP aggregates are as shown in Table 5. Marshall Test was conducted in accordance with code ASTM D6926 - 04. Figure 1 to Figure 3 indicates the influence of Marshall properties of RAP on asphalt concrete mixes.

Table.5 Marshall Properties of asphalt concrete mix with conventional aggregates and Bitumen extracted RAP aggregates

\begin{tabular}{|c|c|c|c|c|c|c|c|}
\hline Sl.No & AC mix with & $\begin{array}{c}\text { Marshall } \\
\text { stability, KN }\end{array}$ & $\begin{array}{c}\text { Flow, } \\
\mathbf{m m}\end{array}$ & $\mathbf{V M A}, \mathbf{\text { VFB, \% }}$ & $\begin{array}{c}\text { OBC, } \\
\mathbf{\%}\end{array}$ & $\begin{array}{c}\text { Bulk density, } \\
\mathbf{g m / c c}\end{array}$ \\
\hline 1 & $\begin{array}{c}\text { Conventional } \\
\text { aggregates }\end{array}$ & 25.9 & 3.87 & 13.6 & 88.94 & 5.3 & 2.3 \\
\hline 2 & $\begin{array}{c}\text { Bitumen } \\
\text { extracted } \\
\text { aggregates }\end{array}$ & 27.11 & 3.81 & 13.60 & 87.57 & 5.2 & 2.29 \\
\hline
\end{tabular}



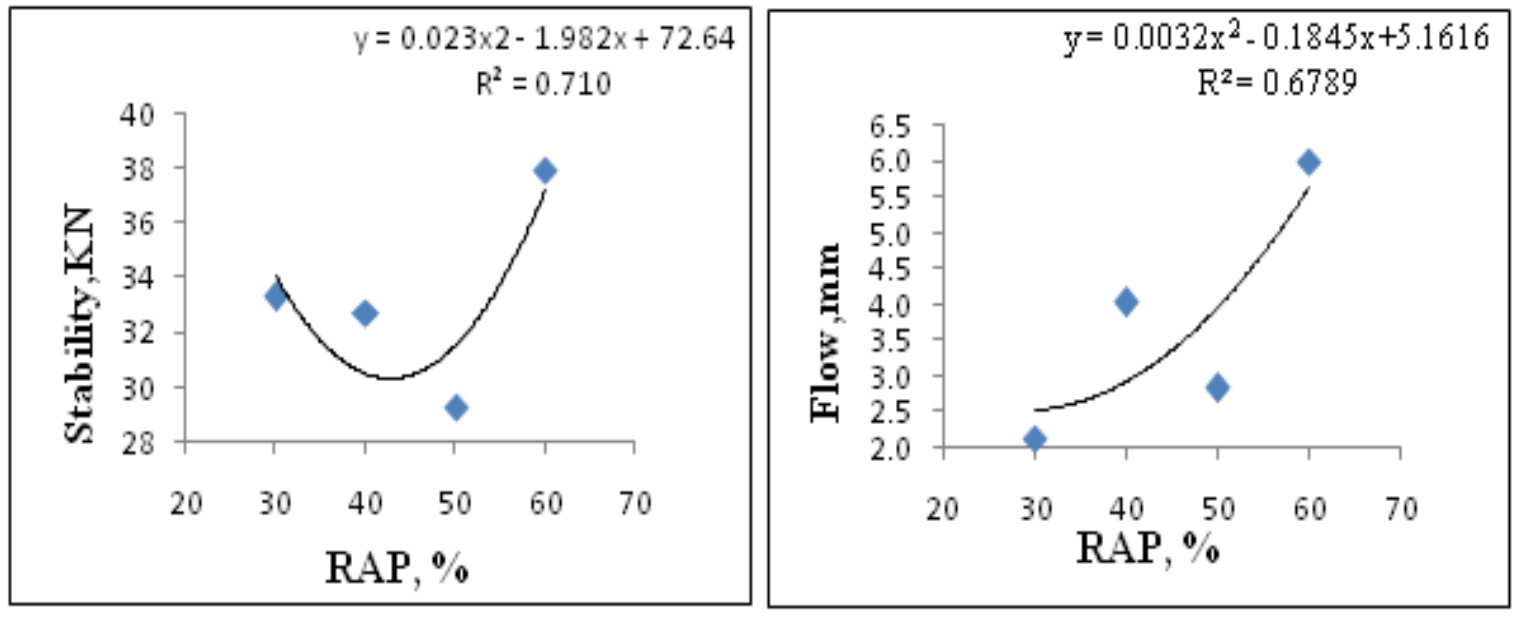

Fig1. Effect of RAP on Marshall Stability and flow of asphalt concrete mixes
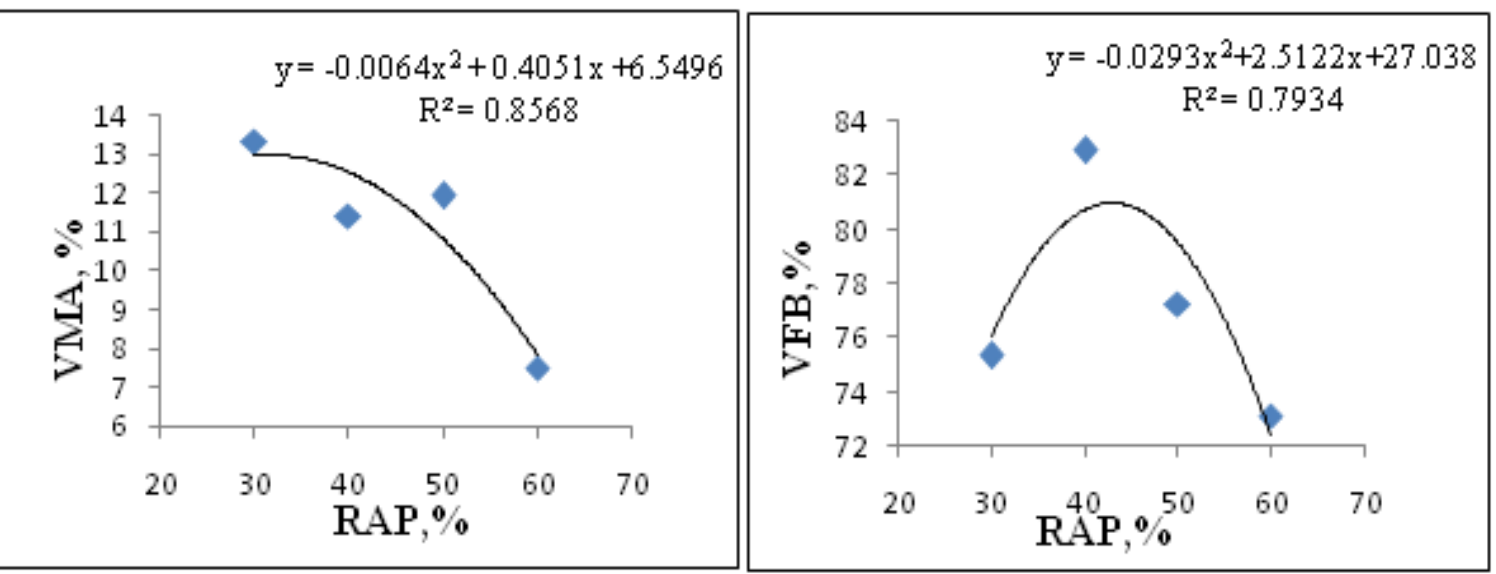

Fig 2.Effect of RAP on VMA and VFB of asphalt concrete mixes
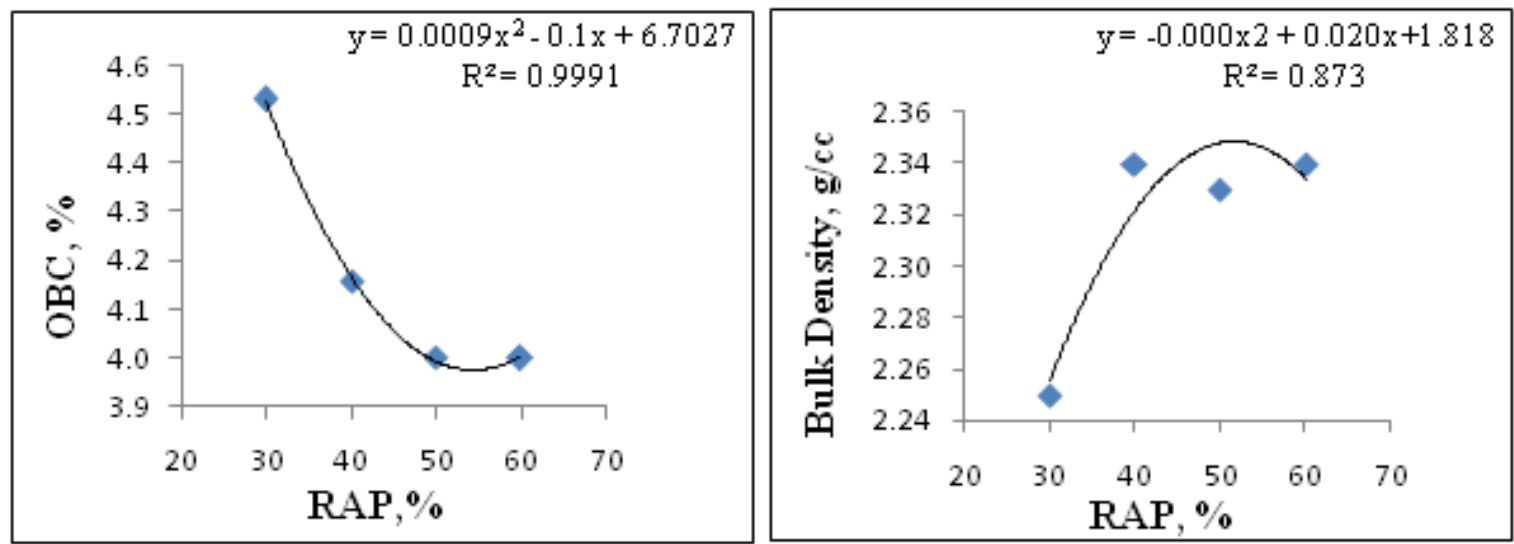

Fig3 Effect of RAP on OBC and bulk density of asphalt concrete mixes 


\subsection{Indirect Tensile Strength Test}

Indirect tensile strength tests were conducted on asphalt concrete mixes at optimum binder content for 30, 40, 50, 60 percentages of RAP aggregates. For comparison asphalt concrete mixes prepared with conventional aggregates and binder extracted RAP aggregates were tested for indirect tensile strength. The tests were conducted on unconditioned specimens at $30 \mathrm{oC}$.

The indirect tensile test is performed by loading a cylindrical specimen with a single or repeated compressive load according to ASTM D 6931 test, which acts parallel to and along the vertical diametric plane. This loading configuration develops a relatively uniform tensile stress perpendicular to the direction of the applied load and along the vertical diametric plane, which ultimately causes the specimen to fail by splitting along the vertical diameter.

\subsection{Indirect Tensile Strength Test Results}

The tests were conducted on the asphalt concrete mixes prepared for both conventional and RAP specimens with 30 , 40, 50, 60 percent without extraction, 100 percent RAP with extraction with test temperature of 300C. Table 6 and 7 shows the indirect tensile strength test results and the same is graphically represented as shown in figure4.

Table.6 Effect of RAP on ITS of AC mixes at $30^{\circ} \mathrm{C}$.

\begin{tabular}{|c|c|c|}
\hline Sl no. & RAP, \% & $\begin{array}{c}\text { Average Indirect } \\
\text { ten sile strength, } \\
\mathbf{N} / \mathbf{m m}^{2}\end{array}$ \\
\hline 1 & 30 & 1.65 \\
\hline 2 & 40 & 1.26 \\
\hline 3 & 50 & 1.09 \\
4 & 60 & 1.13 \\
\hline
\end{tabular}

Table7 Indirect tensile strength test results for 0,100 percent extracted RAP aggregates at $30^{\circ} \mathrm{C}$.

\begin{tabular}{|c|c|c|}
\hline Sl no. & AC mix with & $\begin{array}{c}\text { Aver age Indirect tensile } \\
\text { str ength, } \mathbf{N} / \mathbf{m m}^{2}\end{array}$ \\
\hline 1 & $\begin{array}{c}\text { Conventional } \\
\text { aggregates }\end{array}$ & 0.80 \\
\hline 2 & $\begin{array}{c}\text { Binder extracted } \\
\text { aggregates }\end{array}$ & 0.755 \\
\hline
\end{tabular}

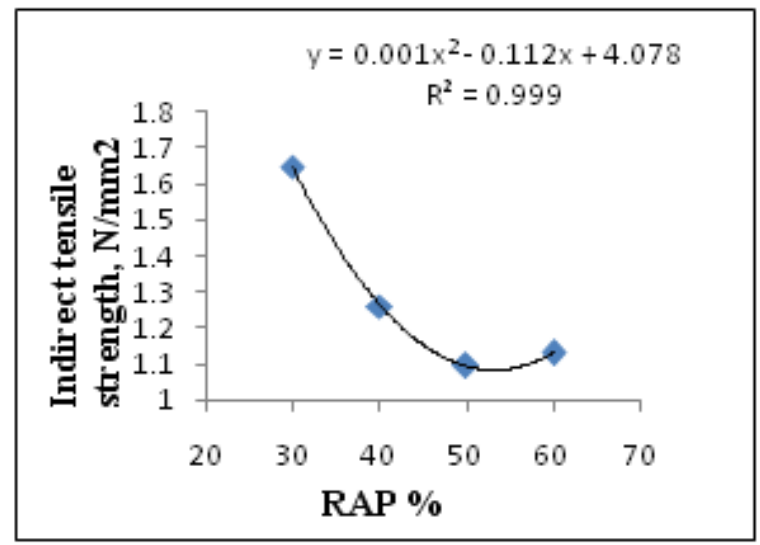

Fig4. Effect of RAP on indirect tensile strength in AC mixes

\section{DISCUSSIONS AND CONCLUSIONS}

Marshall Stability and indirect tensile strength test were conducted on asphalt concrete mixes with $30,40,50$, and $60 \%$ RAP aggregate. For comparison, tests were also conducted on asphalt concrete mixes with conventional and bitumen extracted aggregate. From table 5 and figure 1 to figure 3 following inferences was withdrawn.

1. The Marshall Stability and bulk density of AC mixes initially decreased and further increased with the increase in RAP aggregates. Stability value obtained satisfied the requirements as per Table 500-19, MoRT\&H (IV revision).

2. The flows increased with increase in RAP content and were in the permissible limit as per Table 500-19, MoRT\&H (IV revision). But the AC mix with $60 \%$ RAP showed the maximum flow which was more than the permissible limits.

3. Percentage of voids in mineral aggregates and optimum binder content decreased with the increase of RAP aggregates in AC mixes.

4. Percentage of voids filled with bitumen increased and decreased as the RAP contentment was increased. This was not in permissible limits as per Table 500-19, MoRT\&H (IV revision) due to the presence of bitumen content of RAP.

5. The stability of AC mixes was found to be increased by $28.6 \%, 26.29 \%, 13.16 \%, 46.6 \%$ and $4.67 \%$ for 30,40 , $50,60 \%$ and bitumen extracted aggregates as compared to conventional mixes. Due to the presence of hard aged binder the stability has increased when compared with conventional mix.

6. It was found that optimum binder content decreased by $14.5 \%, 21.5 \%, 23.9 \%, 24.5 \%$ and $1.8 \%$ for $30,40,50$, $60 \%$ and bitumen extracted aggregates as compared to conventional mixes. The presence of bitumen content in the RAP has influenced the optimum binder content to decrease with respect to conventional mix. 
7. Flow was found to be increased by $9.7 \%, 39.5 \%, 18.98 \%$ for $40,60 \%$ RAP content and binder extracted RAP aggregates. Whereas $41.04 \%$ and $21.76 \%$ has decreased for 30 and $50 \%$ of RAP aggregate when compared with conventional AC mixes.

8. Bulk density of asphalt concrete mixes was found to be almost equal when compared with conventional mix and binder extracted RAP aggregates.

9. Indirect Tensile Strength of asphalt concrete mixes was found to be increased by $52.73 \%, 38.09 \%, 28.64 \%$, $30.97 \%$ for $30,40,50$ and $60 \%$. Whereas decreased by $6.12 \%$ for binder extracted RAP aggregates when compared with conventional AC mixes.

\section{REFERENCES}

[1] Freddy L. Roberts, Prithvi S. Khandal, E .Ray Brown, "Hot mix asphalt materials, mixture design and construction” NAPA, Maryland, II Edition, 1996.

[2] Audrey Copeland, "Reclaimed Asphalt Pavement in Asphalt Mixtures: State of the Practice", FHWA-HRT11-021, April 2011

[3] National Cooperative Highway Research Program, synthesis 421, "Recycling and reclaimation of asphalt pavemen"t, Transportation research board, 2011.

[4] Ken Sweeden, "Utilization of Reclaimed asphalt pavement" North Dakota Asphalt conference april 7, 2010

[5] Basic Asphalt Recycling Manual, ARRA- Asphalt Recycling and Reclaiming Association, U S Department of Transportation,2001.

[6] Ministry of Road Transport and Highways (MoRT\&H).Specification for Roads and Bridge work. Government of India, Indian Roads Congress, $4^{\text {th }}$ revision, New Delhi, India,2001.

[7] Laureano R. Hoyos,; Anand J. Puppala,; and Carlos A. Ordonez, "Characterization of Cement-Fiber-Treated Reclaimed Asphalt Pavement Aggregates: Preliminary Investigation" journal of materials in civil engineering C) ASCE ,977-989, july 2011.

[8] Anand J. Puppala,; Sireesh Saride,; and Richard Williammee "Sustainable Reuse of Limestone Quarry Fines and RAP in Pavement Base/Subbase Layers" Journal of materials in civil engineering (C) ASCE ,418429, april 2012. 